\title{
HISTÓRIAS EM QUADRINHOS E O ENSINO DE QUÍMICA: PERCEPÇÃO DOCENTE DE UMA PROPOSTA INVESTIGATIVA
}

\author{
COMICS AND CHEMISTRY TEACHING: TEACHING \\ PERCEPTION OF AN INQUIRY PROPOSAL \\ COMICS Y EDUCACIÓN EN QUÍMICA: PERCEPCIÓN \\ DOCENTE DE UNA PROPUESTA INVESTIGATIVA
}

\author{
LEONARDO ANDRÉ TeSTONI ${ }^{\mathrm{I}}$ \\ SOLANGE WAGNER LOCATELLII ${ }^{\mathrm{II}}$ \\ Simone Alves de Assis Martorano ${ }^{\mathrm{I}}$ \\ Marco Antônio dos Santos ${ }^{I}$ \\ ${ }^{I}$ Universidade Federal de São Paulo (UNIFESP), Diadema/SP - Brasil \\ ${ }^{\text {II } U n i v e r s i d a d e ~ F e d e r a l ~ d o ~ A B C, ~ S a n t o ~ A n d r e ́ / S P ~-~ B r a s i l ~}$
}

\begin{abstract}
Resumo Histórias em Quadrinhos (HQs) fizeram e fazem parte do cotidiano mundial, há décadas. Trata-se de um formato de arte que une, dinamicamente, diversos tipos de linguagens, como a escrita e o desenho, fazendo-as fluir em uma narrativa que busca a identificação com seu leitor. O presente artigo buscou propor uma sequência didática baseada no uso de HQ e analisá-la a partir das percepções do docente que a aplicou. Fundamentada nos princípios do ensino por investigação, estes articulados com os referenciais piagetianos, a sequência didática $(\mathrm{SD})$ procura inserir a $\mathrm{HQ}$ como instrumento capaz de contextualizar e expor uma situação-problema significativa, articulando modelos atômicos com o fenômeno de emissão luminosa por parte de fogos de artifício. A SD foi aplicada em uma turma do $9^{\circ}$ ano do Ensino Fundamental de 2 escolas da cidade de São Paulo. A fala do professor foi analisada a partir da metodologia de análise de conteúdo e quatro categorias emergiram (levantamento das concepções prévias dos discentes, envolvimento dos discentes, socialização dos modelos explicativos propostos e importância da HQ no processo de ensino-aprendizagem), dentre as quais destacamos o papel da SD como facilitadora na aquisição das ideias espontâneas dos alunos, bem como a relevância das Histórias em Quadrinhos para a educação química.
\end{abstract}

Palavras-chave: Histórias em Quadrinhos, Ensino de Química, Ensino Investigativo. 
ABSTRACT Comic books (HQ) have been part of everyday life for decades. It is an art format that dynamically unites diverse types of languages, such as writing and drawing, making them flow into a narrative that seeks identification with its reader. This article aims to present a didactic sequence (DS) in chemistry based on the use of HQ, analyzing the evaluation of DS through the teaching perception of the application with the students. Based on the principles of Piagetian psychology and teaching by investigation, the proposal seeks to insert the comic as an instrument capable of contextualizing and exposing a significant problem situation, articulating atomic models with the phenomenon of light emission by fireworks. DS was applied to a 9th class year of elementary school in 2 schools in the city of São Paulo. The evaluation of DS was carried out by discussing the main results based on the perceptions of the collaborating professor about the process. The teacher's speech was analyzed using the content analysis methodology and four categories emerged, within which we highlight DS as a facilitator in identifying students' previous conceptions, as well as the importance of $\mathrm{HQ}$ in the teaching-learning process of chemistry.

Keywords: Comics, Chemistry Teaching, Inquiry.

RESUMen Los cómics han sido parte del mundo cotidiano durante décadas. Es un formato de arte que une dinámicamente diferentes tipos de idiomas, como la escritura y el dibujo, haciéndolos fluir en una narrativa que busca identificarse con su lector. Este artículo tiene como objetivo presentar una secuencia didáctica (SD) en química basada en el uso de HQ, analizando la evaluación de SD a través de la percepción docente de la aplicación con los estudiantes. Basado en los principios de la psicología piagetiana y la enseñanza por investigación, la propuesta busca insertar HQ como un instrumento capaz de contextualizar y exponer una situación problemática significativa, articulando modelos atómicos con el fenómeno de emisión de luz por fuegos artificiales. DS se aplicó a una clase de escuela primaria en 2 escuelas de la ciudad de São Paulo. El discurso del profesor se analizó en función de la metodología de análisis de contenido y surgieron cuatro categorías, dentro de las cuales destacamos a SD como facilitador en la identificación de las concepciones previas de los estudiantes, así como la importancia de HQ en el proceso de enseñanza-aprendizaje de la química.

Palabras Clave: Cómics; Enseñanza de la química; EnseñanZa investigativa.

\section{INTRODUÇÃo}

\section{Educação químico-científica nos dias atuais}

Tradicionalmente, o Ensino de Ciências vem sendo abordado em um viés compartimentado e memorístico, com o conhecimento científico sendo dividido em conteúdos e áreas estanques, num processo de aprendizagem baseado na memorização de fórmulas e exercícios previamente estabelecidos, em um ciclo de repetições sem significado para o aluno (SASSERON; CARVALHO, 2016).

O Ensino de Química, particularmente, além da problemática acima apresentada, enfrenta especificidades recorrentes (SANTOS; SCHNETZLER, 2003, e.g.), pois necessita da utilização de modelos mentais abstratos, conceitos matemáticos, experimentação e uma 
linguagem própria nas aulas dessa disciplina. Isso requer a utilização de abordagens que possibilitem articular todos esses aspectos, bem como permitir ao aluno transitar entre os níveis representacionais, do concreto (macroscópico) ao abstrato (submicroscópico).

Levando-se em consideração as características acima apontadas do ensino dessa ciência, diversas estratégias vêm sendo estudadas por pesquisadores da área de Educação em Química, buscando uma maior qualidade nos processos pedagógicos inerentes a tais situações. Desse modo, podem ser encontradas abordagens que, em busca de uma aprendizagem com mais significado, tragam inserções de práticas experimentais investigativas (PIERINI, 2015), jogos e atividades lúdicas (CUNHA, 2012), ou mesmo novas interpretações para a linguagem existente entre professor e aluno (MORTIMER; ALVARENGA, 2016).

Com mais de 40 anos, a pesquisa em Ensino de Química, que teve sua origem na Didática das Ciências, evoluiu no ponto de vista metodológico, englobando designs de pesquisa originários das áreas de história, sociologia e psicologia, conseguindo trazer resultados mais fundamentados acerca dos processos didáticos. Como uma subárea reconhecida dentro da Sociedade Brasileira de Química e com publicações específicas da área, a Educação em Química, atualmente, emerge como fonte de debates e sugestões para um contexto nacional marcado pelo desestímulo à formação docente e à aprendizagem $(\mathrm{SCH}-$ NETZLER, 2002).

Nessa linha, enfatiza-se, portanto, a necessidade de repensar-se os conteúdos e a forma como eles vêm sendo ensinados a esse público específico, fruto de um processo, historicamente recente, de ampliação da educação. Dessa forma, é fundamental que o professor seja formado em um ambiente que promova sua autonomia, enquanto possibilitador de novas oportunidades de aprendizagem; apresentando múltiplas possibilidades de apropriações para os conteúdos abordados; oportunizando ao aluno momentos de repensar suas ideias e seus conceitos, o que, de acordo com Locatelli e Arroio (2013), são estratégias metacognitivas que oportunizam ao estudante a possibilidade de ocorrer essa autorregulação favorecendo a (re)construção da aprendizagem.

Com base no exposto, o presente artigo, diante do contexto descrito, busca propor uma sequência didática em química baseada na utilização de Quadrinhos. Baseada nos princípios da psicologia piagetiana e do Ensino por Investigação, a atividade proposta procura inserir a HQ como instrumento capaz de contextualizar e expor uma situação-problema significativa, articulando modelos atômicos com o fenômeno de emissão luminosa por parte de fogos de artifício. A partir da SD aplicada em turmas do $9 .{ }^{0}$ ano (EF), pretende-se analisar a avaliação dessa SD por meio da percepção docente dessa vivência junto aos alunos.

\section{Histórias em quadrinhos e o ensino}

Desde sua popularização, as Histórias em Quadrinhos trazem, para seus leitores, elementos icônicos que buscam sua interação com a narrativa apresentada. Desse modo, as HQs acabam funcionando como uma forma de educação informal (ANSELMO, 1975). Ainda segundo o autor, apesar da existência (nos anos 1970) de correntes que ligavam os Quadrinhos à incitação da criminalidade, vício e subversão, fica claro o estímulo dado pelas HQs à imaginação, além de favorecer diversos processos cognitivos como, por exemplo, a aprendizagem, a linguagem, a tomada de decisões, entre outros, por parte de seu leitor. 
Desse modo, as HQs vêm se tornando um instrumento de potencial relevância no processo pedagógico, independentemente da faixa etária (KUNDLATSCH, 2019). Em rápida revisão bibliográfica realizada nos eventos da área de Ensino de Ciências, por exemplo, o autor aponta um aumento significativo (a partir de 2001) das pesquisas envolvendo Quadrinhos e Educação Científica, com aplicações desde os anos iniciais do Ensino Fundamental até o nível superior.

Do ponto de vista educacional, as HQs assemelham-se a uma atividade lúdica que se apoia em dois pilares: a catarse e o desafio. Nessa linha, Testoni et al. (2017) pontuam que os Quadrinhos, enquanto atividade lúdica e educacional, permitem ao leitor/estudante um processo catártico, ou seja, um despojamento do estresse e tensões, o que facilita sua identificação com o material. Ainda nesse raciocínio, e tão importante como o primeiro pilar, é a importância da HQ apresentar algum tipo de desafio ao seu leitor, o que nos leva a inferir sobre a importância da construção da narrativa, que pode apresentar situações-problema de cunho científico-educacional em seu enredo, visando a um melhor aprendizado.

Tão fundamental quanto o papel catártico e desafiador, enquadra-se a possibilidade de o leitor/estudante identificar-se com o personagem da HQ, o que o levaria a, por assim dizer, entrar na história e viver, como se fossem reais, as angústias e desafios do personagem (BOYLE, 2012). Segundo a autora, tal identificação propicia a aproximação com o tema abordado pela narrativa, trazendo possibilidade de uma aprendizagem mais significativa.

Com base no exposto considerou-se, neste trabalho, que a narrativa de uma História em Quadrinhos é um espaço frutífero para a proposição de situações-problema. Para a análise de tais situações, recorreremos a elementos da psicologia piagetiana, que alicerçam a proposta investigativa, apresentada a seguir.

\section{Noções sobre a teoria de equilibração piagetiana}

Jean Piaget, em estudos realizados desde a primeira metade do século XX, propôs o desenvolvimento cognitivo humano dividido em estágios pré-definidos (PIAGET, 1976). Segundo Piaget (1976) temos 3 estágios do desenvolvimento humano, quais sejam: 1) Sensório-Motor, englobando crianças até 2 anos de idade, em que as funções simbólicas ainda se encontram em desenvolvimento, o que gera comportamento não baseado em ligações cognitivas. 2) Operações Concretas, caracterizadas pelo desenvolvimento de funções simbólicas, permitindo uma interiorização direta e rápida de operações, como as conservações de massa e volume. 3) Operações formais, que permitem ao indivíduo a realização de operações abstratas e suas relações com o mundo, manejando hipóteses e raciocínios não diretos.

Com base nesses estágios propostos, o autor propõe que o desenvolvimento cognitivo ocorreria em um sucessivo processo de equilibrações majorantes, ou seja, um estágio de desenvolvimento é substituído por esquemas mais completos se comparados aos anteriores, possibilitando melhores explicações de fenômenos.

Assim, a teoria de equilibração piagetiana pressupõe uma interação entre o sujeito e o objeto de conhecimento, criando patamares cognitivos cada vez mais estáveis. Portanto, em um viés pedagógico, é necessário que o estudante seja estimulado a interagir com o objeto (aqui, compreendido como uma situação educacional), sendo função do docente o incentivo e orientação para se trabalhar com tal estímulo. 
Ainda nessa linha, tal estímulo deve ser passível de romper esquemas cognitivos prévios, já trazidos pelos estudantes e, muitas vezes, carregados de visões pré-científicas ou, mesmo, errôneas. Nessa linha, é importante que o docente proponha situações desafiadoras que atuem diretamente nesses esquemas prévios, focando pontos que estes não sejam capazes de explicar.

Segundo Piaget (1976), a relação do indivíduo com o objeto de conhecimento se dá por intermédio do processo de adaptação, que pode ocorrer de duas formas: (a) assimilação, que prevê a incorporação de um elemento exterior em esquemas cognitivos já existentes e (b) acomodação, que prevê a necessidade de alteração de esquemas cognitivos para incorporar um fato novo apresentado, gerando uma perturbação no sistema. Apesar de um pretenso caráter linear do processo, é importante salientar que o mesmo ocorre de maneira complementar, ou seja, a assimilação e a acomodação podem ocorrer simultaneamente, com um ajustamento progressivo das estruturas internas.

Como exposto, o processo de desenvolvimento cognitivo pressupõe o desequilíbrio de esquemas mentais anteriores, buscando sua evolução, devido à existência de fatos novos. Tais perturbações, segundo Piaget (1976), podem ser classificadas quanto à sua natureza: as lacunas e conflitos.

No caso das lacunas, trata-se de uma situação em que as estruturas cognitivas não têm elementos para explicar o fato novo surgido, ou seja, ocorre uma insuficiência de esquemas conceituais para a compreensão do fenômeno (SILVA, 1995). Para o autor, a lacuna se torna uma perturbação quando se trata da ausência de condições necessárias para concluir uma ação indispensável à resolução da situação-problema exposta. Como resposta, o indivíduo poderá criar um novo sistema explicativo para os fatos novos.

Já os conflitos representam uma incompatibilidade entre as ideias surgidas do meio externo e aquelas existentes nos esquemas cognitivos do indivíduo. Nesse caso, segundo Piaget (1976), o sujeito poderá reagir de três formas diferentes: (a) conduta alfa, considerada uma reação de compensação, onde o indivíduo nega o conflito gerado e continua utilizando os esquemas mentais anteriores; (b) conduta beta, em que o conflito consegue ser incorporado a algum esquema mental, sem necessidade de alterações severas e (c) conduta gama, em que o conflito, utilizando a reorganização iniciada em beta, consegue gerar alterações de grande monta nos esquemas mentais do sujeito, sendo necessárias mudanças nesses esquemas, para incorporar o conflito surgido.

De maneira geral, ao ocorrer a interação entre sujeito e objeto de conhecimento, pretende-se que os esquemas conceituais anteriores evoluam para esquemas mais completos e complexos, em um processo de equilibração majorante, conseguindo-se, assim, modelos explicativos mais eficazes para a explicação de fenômenos ocorrentes.

Diante do quadro teórico anteriormente exposto, acredita-se neste trabalho, que o Ensino de Química, utilizando-se das sequências didáticas investigativas, possa favorecer o desenvolvimento cognitivo dos estudantes.

\section{Sequências didáticas investigativas}

Sequências Didáticas (SD) são "um modo de o professor organizar as atividades de ensino em função de núcleos temáticos e procedimentais" (ARAÚJO, 2013, p.323). 
Ainda para a autora, a sequência didática clarifica a condução metodológica de uma série de fundamentos teóricos sobre o processo de ensino e aprendizagem. Assim sendo, as SD caminham conjuntamente com um referencial teórico de apoio, sendo importante que todos os pontos dessa sequência sejam coerentes com as ideias trazidas pelos referenciais adotados.

Nessa linha, em corroboração com a psicologia piagetiana, foi elaborada uma sequência didática baseada nos princípios do ensino investigativo (CARVALHO, 2013). Para a autora, em propostas investigativas, o aluno tem participação ativa em seu processo de ensino e aprendizagem, o que representa a base de todas as teorias construtivistas que dão fundamentação às propostas de ensino por investigação. Logo, é preciso considerar que, além do aluno ser construtor de seu conhecimento, é importante salientar que o conhecimento a ser ensinado deve partir do conhecimento trazido para a sala de aula, decorrente de sua vivência.

Para Masetto (1996), no construtivismo, o aluno é protagonista de seu processo de aprendizagem, desempenhando participação ativa em atividades que envolvam a formulação de hipóteses para resolução de problemas, a manipulação de materiais experimentais, e a interação com os demais colegas de classe e com o professor. O ensino é baseado no ensaio e erro, na pesquisa, na investigação, na solução de problemas por parte do indivíduo e não na aprendizagem de fórmulas, nomenclaturas, definições, etc. Assim, a primeira tarefa da educação consiste em desenvolver o raciocínio (MASETTO, 1996).

Para Carvalho (2013), tais propostas investigativas possuem uma estrutura básica, e, como o próprio construtivismo, possuem alguns pressupostos, como: (1) apresentação do problema para investigação; (2) levantamento de hipóteses; (3): teste das hipóteses com a manipulação do material experimental; (4) a tomada de consciência do aluno em relação ao problema proposto; (5) a explicação do problema.

A apresentação de um problema no início da atividade investigativa contribui para que sejam mobilizados conhecimentos prévios em função do desafio apresentado pelo professor, levantando possíveis hipóteses a fim de se resolver o problema proposto. O questionamento inicial, em tais propostas didáticas, desempenha a função de nortear o processo investigativo.

No que se refere à manipulação do material experimental ou material didático, existem algumas possibilidades. Como aponta Carvalho (2013), o recurso a ser utilizado para apresentar o problema pode ser um texto, uma figura ou aparato experimental, tomando o devido cuidado para que os alunos possam resolvê-lo sem se perder. Ainda segundo Carvalho (2013), é interessante que o material a ser manipulado durante a aula possibilite que a situação proposta seja explorada de diferentes maneiras para a resolução do problema, permitindo o teste de hipóteses, pois é a variação das ações sobre o problema que fornecerá diferentes observações, bem como favorecerá discussões sobre a questão proposta fomentando diferentes pontos de vista sobre o problema, com diferentes argumentos para sustentar tais pontos de vista. 
As discussões precisam chegar até a explicação do problema proposto, ou fenômeno de estudo. Pode-se notar esta fase quando, segundo Carvalho (2013), os alunos deixam de serem eles próprios e passam a falar do fenômeno como um agente.

Na elaboração da SD investigativa, com a abordagem da HQ, tentou-se levar em consideração essas características do Ensino por Investigação, discutidas por Carvalho (2013), como pode ser observado na descrição da SD feita a seguir.

\section{DESENVOLVIMENTo}

\section{Percurso metodológico}

A SD investigativa foi aplicada em quatro turmas do $9^{\circ}$ ano do Ensino Fundamental, de duas escolas da cidade de São Paulo (uma pública e outra privada) contando com um total de 120 alunos. Como já anunciado, para o presente artigo, optamos por apresentar uma discussão dos principais resultados alicerçados na percepção docente (BRITO; COSTA, 2010; GOUW; BIZZO, 2016; MARTINS; MACHADO, 2016) do professor colaborador sobre o processo, além de material artístico produzido pelos discentes. O professor Ivan (nome fictício para preservar o anonimato) é formado em química, atua como professor há mais de 30 anos, tanto na rede pública como privada, e colaborou nessa pesquisa como docente efetivo das turmas de ambas as escolas.

Para a obtenção das citadas percepções, solicitou-se que o Professor Ivan respondesse, no formato de áudio, questões sobre suas impressões sobre o processo de ensino-aprendizagem proposto. As respostas obtidas foram analisadas à luz da Análise de Conteúdo (BARDIN, 2011). Nessa linha, o áudio analisado, primeiramente passou por uma organização inicial, constituindo o corpus da pesquisa, para, posteriormente, ser explorado e categorizado, constituindo-se os episódios de interesse acadêmico (TESTONI et al., 2017), cujos alguns excertos serão apresentados na discussão dos resultados, como exemplificação e suporte da análise.

\section{A sequência didática proposta e a HQ utilizada}

Os Quadrinhos criados para a presente investigação têm o objetivo de inserir o desafio lúdico na narrativa da HQ criada, buscando que tal desafio, aqui considerado como conflito cognitivo, atue diretamente nas concepções prévias dos estudantes no tocante ao fenômeno abordado, possibilitando que os demais elementos da sequência didática atuem na alteração dos esquemas mentais vigentes, buscando sua evolução para patamares mais completos e capazes de explicar o desafio contido na História em Quadrinhos. Em suma, a HQ (figura $1^{1}$ ) proposta foi confeccionada considerando-se os elementos universais de formatação quadrinística, além de narrativa com conteúdo químico, onde insere-se a situação-problema a ser discutida pelos discentes.

\footnotetext{
1 Disponível em https://docs.google.com/document/d/1yZPilThrVBGUXY45dss8zrzTEwbzuG3y9W-1io19S28/edit?usp=sharing)
} 


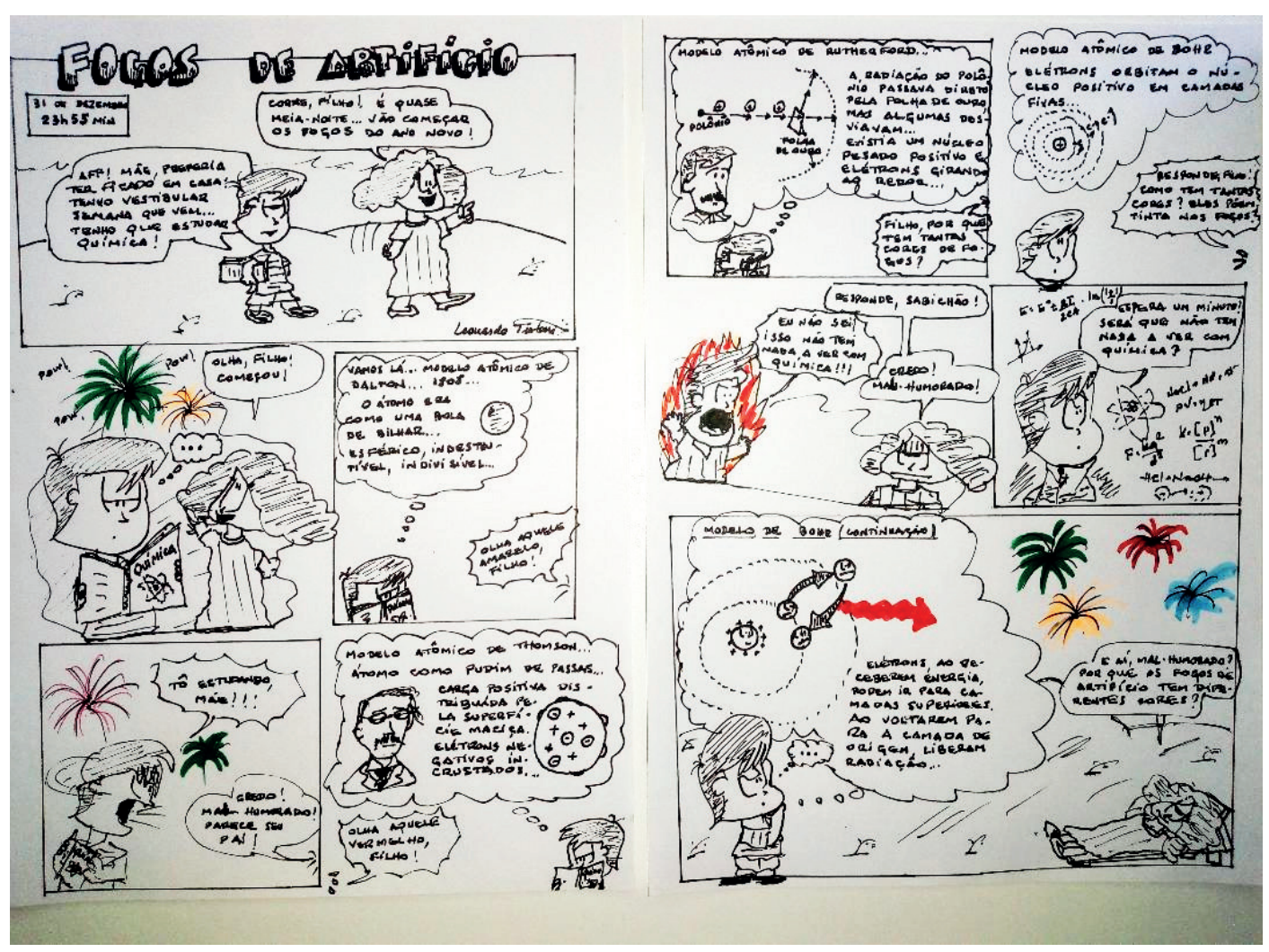

Figura 1 - HQ utilizada. Fonte: primeiro autor

A SD apresentada a seguir é dividida em 4 aulas de 50 minutos, abordando a temática sobre modelos atômicos. Face à complexidade do tema, a presente SD é sugerida para turmas dos anos finais do Ensino Fundamental ou Ensino Médio, que já tenham tido algum contato com atomística.

\section{Aula 1 - Concepções prévias dos alunos}

Dentro de uma proposta de ensino investigativo (CARVALHO, 2013), inspiradas nas ideias piagetianas (PIAGET, 1976), a presente aula busca delinear as concepções espontâneas dos estudantes, de acordo com as respostas dadas a um questionário inicial, que busca observar a noção de modelo atômico apresentada por eles.

À vista disso, é solicitado que desenhem um átomo e expliquem a ilustração feita. Segundo Vasconcellos et al. (2016), esperam-se respostas majoritárias representando o átomo como um sistema planetário, tal qual proposto por Rutherford, porém esperam-se em menor proporção modelos similares ao de Thomson e Dalton, também frequentes na visão de alunos do Ensino Médio, segundo os autores.

Nesse momento, é importante que o professor analise não apenas os desenhos produzidos, mas as explicações adjuntas, pois, segundo Vasconcellos et al. (2016), é possível uma representação planetária de átomo, porém uma explicação mais próxima de Dalton, haja vista que o modelo planetário se tornou quase que um símbolo para a área científica, mas não garante que o estudante, ao usá-lo, possua entendimento de seu significado. 
Aqui recomenda-se ao professor uma discussão sobre o que são modelos em química, uma vez que "modelos são, ao mesmo tempo, ferramentas e produtos da ciência" (FERRERA; JUSTI, 2008, p.32). As mesmas autoras abordam que trabalhar com modelos irá proporcionar ao estudante compreender sobre química bem como sobre ciência. Castilho, Silveira e Machado (1999) apontam a importância de se tratar do caráter provisório da ciência; ao retomar sobre os modelos atômicos trazidos pelos alunos, seria importante fazer essa discussão, proporcionando a eles perceberem que a ciência não é pronta e acabada, tampouco indiscutível. Isso porque os modelos são construtos humanos e vão evoluindo dentro de um contexto cultural e histórico, Moreira (2014) justamente adverte sobre isso, que em geral, os modelos não são considerados dessa forma, bem como os conceitos do próprio modelo são por vezes ignorados. Considerou-se, portanto, oportuna essa aula para retomar esses conceitos ou (re) construí-los à luz da proposta realizada.

\section{Aula 2 - Utilizando a história em quadrinhos}

A HQ apresentada busca retratar uma situação-problema envolvendo a temática atomística. Assim, a narrativa das HQs traz uma mãe e seu filho, que está às vésperas do exame vestibular, observando a queima de fogos de artifício durante uma virada de ano. A ideia central do Quadrinho é trazer à tona a discussão sobre a variedade de cores presentes nos fogos de artifício e uma possível explicação para tal fenômeno.

É importante ressaltar que as HQ são diferentes de outros materiais como, por exemplo, os livros didáticos, não apenas no formato da apresentação do conteúdo, mas também pela possibilidade em se contar uma história, em que o leitor tem a oportunidade de usar a sua imaginação, de se colocar no papel do personagem e, ainda tentar resolver a situação-problema proposta.

A HQ não responde à situação-problema, mas tem o objetivo de contextualizá-la ao leitor/ estudante, com objetivo de por em conflito cognitivo os modelos mentais iniciais discente (PIAGET, 1976), para que este busque a explicação, num processo de construção da aprendizagem, com o levantamento e teste de hipóteses. Dessa maneira, para a citada aula, é sugerido que o professor forneça uma cópia da História em Quadrinhos aos alunos, para que eles façam, em um primeiro momento, uma leitura individual da mesma.

Na sequência, solicita-se que se dividam em grupos e discutam a situação-problema exposta na HQ, ou seja, "por que os fogos de artifício têm diferentes cores?" O trabalho em grupo é primordial nesse caso, pois ainda de acordo com os princípios do Ensino por Investigação (CARVALHO, 2013), é no grupo que os alunos terão que argumentar sobre suas hipóteses, para o convencimento dos demais, tal qual ocorre na comunidade científica. Durante a discussão é importante que o professor circule entre os grupos para orientar as discussões, bem como questionar os modelos explicativos dos estudantes sobre seu potencial para desvendar o fenômeno tratado, assumindo um papel mediador no processo.

Após o término da discussão coletiva, é importante que o professor sistematize as propostas explicativas surgidas, a fim de socializar com todos na sala de aula. Tal ação é valiosa, para que os grupos ajustem seus modelos explicativos com base na exposição de outras maneiras de explicar o fenômeno, enriquecendo a busca pela conclusão. 


\section{Aula 3 - Sistematizando as ideias dos alunos}

Neste momento, é importante o docente relembrar as ideias obtidas pelos alunos na aula anterior, expondo os modelos explicativos propostos, após as discussões realizadas. Assim, pode-se registrar no quadro os raciocínios apresentados, para que possam ser consultados e, se necessário, alterados, no decorrer da atividade.

$\mathrm{Na}$ aula em questão, sugere-se que os estudantes se reúnam nos mesmos grupos de discussão da aula anterior, discutam com suporte em textos disponíveis na internet e pré-selecionados pelo docente e que abordem o histórico e a composição dos fogos de artifício.

Nesta etapa, o debate é de suma importância para que os discentes relacionem a luminosidade colorida dos fogos de artifício ao tipo de sal utilizado. Com a chegada dessa conclusão (que diferentes sais emitem luminosidades de cores diferentes), o docente deve retomar os modelos explicativos obtidos após a leitura da HQ, associando a luminosidade de cada fogo de artifício à energia liberada na transição eletrônica, que é característica de cada elemento químico. Nesse momento, é pertinente que o professor ressalte que uma explicação no nível submicroscópico (transição de elétrons) foi necessária para se compreender um fenômeno no nível macroscópico (luz colorida visível). Al-Balushi (2013) sinaliza a pouca habilidade que os estudantes apresentam para transitar do nível macroscópico (fenômeno) para o explicativo envolvendo átomos, moléculas, íons (submicroscópico), o que pode ser discutido aqui com os alunos.

À guisa de conclusão, o professor pode utilizar vídeos, também pré-selecionados pelo docente - aqui, sugere-se "A Química dos Fogos de Artifício", em que a explicação sobre o fenômeno é sistematizada, incluindo as cores produzidas por diversos elementos químicos presentes nos efeitos pirotécnicos.

\section{Aula 4 - Proposta de avaliação: alunos desenham suas próprias $H Q s$}

Para avaliar a sequência proposta, sugere-se que os alunos desenhem suas próprias Histórias em Quadrinhos, com o objetivo de continuar a HQ apresentada originalmente (que não tem final).

Dessa forma, espera-se que os estudantes consigam utilizar a apropriação do conteúdo trabalhado, para organizar o final da HQ inicial, respondendo, na forma de Quadrinhos, o motivo pelo qual os fogos de artifício apresentam diferentes cores. Como sugestão, pode-se fazer uma apresentação dessas HQs, com discussão coletiva, onde serão (re)discutidos os conceitos envolvidos, onde os próprios alunos poderão se autorregular (etapa metacognitiva) a partir dos apontamentos realizados.

A sugestão dos discentes confeccionarem suas próprias HQ baseia-se no fato de que este tipo de arte apresenta uma linguagem escrita sintética e de fácil acesso, apresentando sua mensagem principal na linguagem icônica (desenhada). Tal situação, em nosso ponto de vista, tem validade como avaliação do processo, uma vez que o estudante deve possuir um domínio do tema abordado, para conseguir transformá-lo em uma narrativa quadrinística, na qual a informação deve ser dada de forma sucinta, porém correta e completa. 


\section{Discussão dos Resultados - EXPLORANDO A PERCEPÇÃo DOCENTE E AS HQS DOS ESTUDANTES}

Conforme já explanado, fizemos uma opção metodológica em analisar a percepção de um docente no tocante à aplicação da SD investigativa, desenvolvida nas 4 aulas explicadas anteriormente.

Conforme Gouw e Bizzo (2016), a análise de percepções docentes (no caso do artigo em tela) é uma importante ferramenta para uma maior aproximação com atitudes, e não só conteúdos, o que foi apresentado pelo entrevistado. Nessa mesma linha, Martins e Machado (2016) trazem as interpretações de percepções docentes como um caminho qualitativo-exploratório, que permite uma aproximação inicial com a problemática proposta, trazendo uma manifestação mais livre do(s) sujeito(s) que proporcionará (ão) a fonte dos dados. Dessa forma, com relação à utilização de percepções docentes, infere que "é possível compreender dificuldades e contradições [...]" (MARTINS; MACHADO, 2016, p.595), surgidas no locus da pesquisa e que foram apropriadas pelos sujeitos observados.

Brito e Costa (2010) já traziam a importância do estudo das percepções docentes como possível instrumento, passível de uma multiplicidade de definições, porém eficaz na demonstração da forma como indivíduos percebem (coletivamente ou individualmente) seu entorno cultural. Para os autores, "[...] entende-se que conhecer e compreender as dinâmicas [...] por meio das percepções docentes [...] é um campo teórico rico de análise, em especial na escola pública" (BRITO; COSTA, 2010, p.503).

Assim, a partir das respostas do Professor Ivan ao questionário, surgiram 4 categorias a saber: levantamento das concepções prévias dos discentes, envolvimento dos discentes, socialização dos modelos explicativos propostos e importância da HQ no processo de ensino-aprendizagem. Na sequência, trataremos de cada uma dessas categorias, mediante apresentação de excertos da fala do docente, que exemplificam cada uma delas.

A primeira categoria que emergiu dos dados remete às ideias de Piaget (1976) e refere-se ao levantamento das concepções prévias dos discentes, no tocante ao fenômeno luminoso da explosão dos fogos de artifício. Segundo o próprio docente, que questionou as turmas:

\footnotetext{
"[os alunos]a maioria tinha (sic) uma ideia de que as cores vinham de uma mistura dos elétrons ou prótons. De acordo com a quantidade e forma dessa mistura, as cores produzidas seriam diferentes [...] achei interessante esse pensamento, porque tem a ver com os elétrons, só que eles usaram uma explicação que eu nunca tinha visto."
}

A concepção apontada vai ao encontro com concepções prévias já previstas pela literatura (COSTA GONDIM; MENDES, 2012), onde observa-se uma confusão entre os níveis macro e submicroscópico (inclusive, entre docentes), considerando-se a possibilidade de mistura entre partículas elementares. É possível também que os alunos estejam sinalizando uma espécie de transmutação na mistura de elétrons ou prótons (ARDERSSON, 1986), uma concepção já bastante pesquisada na literatura acerca de atomística. Nesse ponto, vale salientar a importância do professor em propor atividades pedagógicas que busquem refutar tal modelo mental, trazendo lacunas e conflitos cognitivos (PIAGET, 1976), que permitam a evolução conceitual do estudante. 
Na continuidade da aplicação da sequência didática, o Professor Ivan relata a reação dos alunos ao receber a HQ.

“[...] foi algo muito legal...[os alunos] pareciam não acreditar que uma História em Quadrinho (sic) ia ser utilizada na aula de Química [...] é como se fosse algo pertencente a outro mundo [...] eles olhavam, manuseavam, mostravam os desenhos e caretas dos personagens para os colegas, davam risada [...] nem precisei pedir para formarem grupos, logo após a leitura, [os alunos] já se aglomeraram e começaram a discutir a história."

O episódio anterior possibilita a observação, a partir da percepção docente, do envolvimento dos discentes, quando da leitura da HQ. Em corroboração com Boyle (2012), é possível inferir sobre a imersão do leitor no enredo contado, como se ele próprio fizesse parte real da narrativa. Tal fato é essencial para que a situação-problema inserida no Quadrinho possa se tornar um desafio legítimo para o aluno-leitor.

Nessa linha, corroboramos com trabalhos anteriores (TESTONI, 2015), onde observa-se a importância de alunos imergirem no material didático (Histórias em Quadrinhos, Teatro, Literatura, por exemplo), identificarem-se com os personagens e situações expostas, para uma significação maior do processo de aprendizagem.

A situação didática proposta pela HQ, inclusive e de acordo com o docente, é discutida espontaneamente pelas turmas, conforme pode ser observado no episódio a seguir.

"Como eles [os alunos] começaram a se reunir em grupos de forma espontânea, a discussão do problema proposto na historinha começou a ser discutido de forma coletiva [...] em algumas salas, a discussão tomou a sala toda, vários queriam colocar sua explicação para o que acontecia [...] começavam a recapitular modelo [atômico] por modelo, buscando a resposta."

A motivação, instigada pela forma como a situação-problema foi exposta, nos remete, novamente, ao caráter lúdico e desafiador da HQ (TESTONI, ibidem), mobilizando os discentes ao redor da problemática proposta. A discussão coletiva descrita torna-se imprescindível para a socialização dos modelos explicativos propostos (CARVALHO, 2013), possibilitando um ambiente de aprendizagem frutífero para a troca de informações e aprimoramentos das ideias e início da solução da situação-problema, como posto a seguir.

\footnotetext{
"Quando eles [alunos] foram revendo os modelos atômicos na historinha, notaram que o único que previa a emissão de luz era o de Bohr, então ficaram mais nele [...] chegaram na conclusão que a luz dos fogos de artifício vinha (sic) da transição dos elétrons entre as órbitas.
}

É possível observar que o envolvimento narrado pelo docente possibilitou trocas de informações e proposições de modelos explicativos, alavancando o grupo de estudantes a relacionar as emissões luminosas com as transições eletrônicas. O ambiente de discussão continua, agora, com a criação de explicações para as diferentes cores observadas nos fogos de artifício, conforme exposto abaixo. 
Eu até perguntei: - Mas e as cores diferentes? De onde vinham? Eles levantaram a hipótese de que seriam de átomos diferentes, porque o movimento dos elétrons seria diferente [...] gesticulavam, mostravam o elétron indo e voltando [...] foi muito legal ver eles (sic) chegando nesse raciocínio. Depois, com o vídeo e o texto, ficou mais fácil sistematizar tudo"

O excerto acima, à guisa de conclusão, permitiu uma visualização da aproximação dos estudantes com as propriedades mais específicas da matéria, aqui representada pelos diferentes espectros de emissão, característicos de cada elemento químico. A percepção docente acima também permitiu inferir acerca da importância da HQ no processo de ensino-aprendizagem.

Tal facilitação pode ser vislumbrada por meio uma abordagem mais visual e interativa quanto à compreensão dos modelos atômicos e sua relação com a resolução da situação-problema proposta, mediante um ambiente de discussão e levantamento de hipóteses adequadas ao fenômeno proposto.

A narrativa fornecida pelo professor permitiu-nos, por intermédio da análise de suas percepções docentes, enxergar o ambiente educacional e algumas de suas nuances, trazendo à tona o papel fundamental da História em Quadrinhos, como elemento instigador de situações-problema, motivando os estudantes com aspectos lúdicos e catárticos, inserindo-os na narrativa (e na solução dos desafios propostos) por meio de sua formatação universal e elementos psicolinguísticos.

As conclusões acima, alicerçadas pelas percepções do professor, podem ser reforçadas pela análise exploratória das Histórias em Quadrinhos confeccionadas pelos estudantes, com o intuito de continuar a HQ inicial (que trazia o questionamento em seu último quadro). A solicitação para que os discentes elaborassem seus próprios Quadrinhos (Figura 2) vem do fato de que o formato adotado pela HQ traz a necessidade de diálogos e exposições icônicas diretas, deixando clara a mensagem principal.
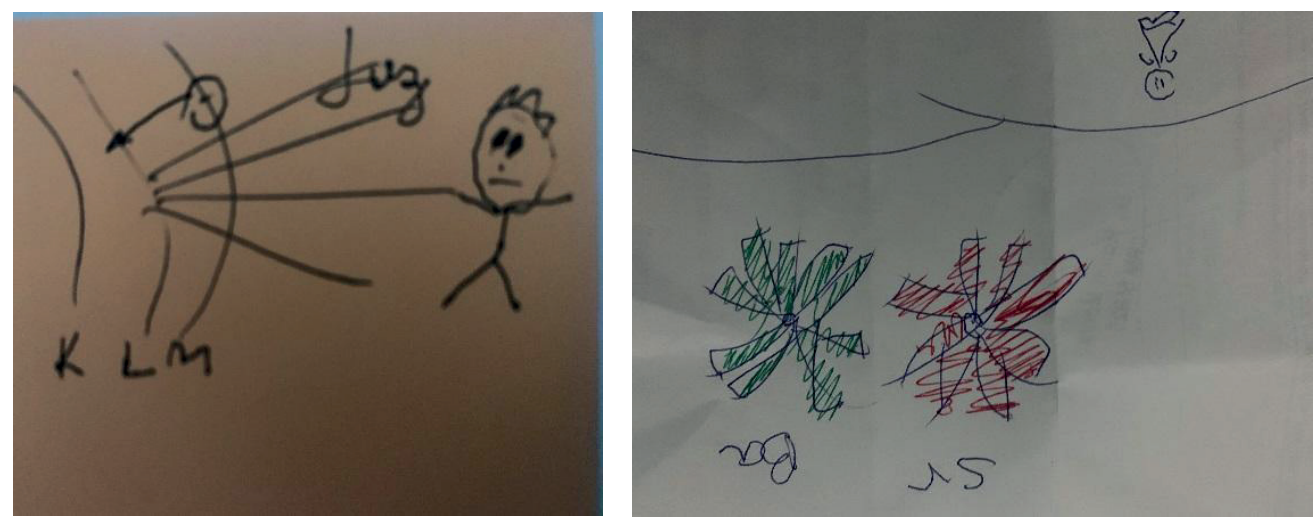

Figura 2. Exemplos de HQs confeccionadas pelos estudantes.

Desse modo, a HQ dos alunos, enquanto instrumento de avaliação, permitiria analisar a presença da articulação entre os conceitos trabalhados na SD. Enquanto instrumento de pesquisa, tais HQs nos permitiram extrair elementos que corroboraram com as percepções docentes, elencando indícios de aprendizagem, como, por exemplo, a inserção de símbolos 
de elementos químicos associados com as cores características do teste da chama de cada elemento, ou ainda, desenhos de transições eletrônicas, com liberação de energia luminosa, conforme pode ser observado na figura anterior, ratificando o papel significativo das HQs no processo de ensino-aprendizagem pontuado pelo docente.

\section{CONCluSÃo}

O presente artigo buscou propor uma sequência didática, de cunho investigativo, cujo alicerce foi a utilização de uma HQ como disparadora de um conflito cognitivo no leitor/ estudante, apoiando-se nas ideias de Piaget. Paralelamente, as percepções do docente com relação à aplicação da SD foram analisadas. Nessa proposta, o Quadrinho teve o papel de contextualizar e expor, inicialmente, a situação-problema ao discente, o que possibilitou $o$ envolvimento dos estudantes, conforme pontuado pelo docente. Tal situação buscava abordar, do ponto de vista atomístico, a problemática envolvida nas diversas cores presentes na explosão de fogos de artifício. A continuidade da sequência proposta visava, sempre em um caráter investigativo, que os estudantes discutissem em grupos sobre os possíveis modelos explicativos para a aludida situação, baseados na orientação do professor, bem como em materiais auxiliares, como textos e vídeos. Segundo o professor, foi possível e sinalizado por ele, a socialização dos modelos atômicos sugeridos pelos estudantes, permitindo o (re)pensar das ideias, uma habilidade metacognitiva importante nessa (re)construção de conceitos.

Devido ao caráter universal e popular do Quadrinho, além de seu potencial desafiador, sua utilização, em nosso ponto de vista, é compatível com a educação básica, haja vista a HQ fazer parte do cotidiano discente, o que pudemos observar durante a aplicação da SD. Além disso, ao se utilizar a História em Quadrinhos como um primeiro contato entre o aluno e o tema químico tratado, pode-se evitar uma relação tradicional de apresentação do conteúdo, podendo mostrar ao discente que a química se encontra em seu dia a dia, inclusive, como enredo de uma $\mathrm{HQ}$, bem como propiciar uma estratégia de levantamento de concepções prévias que podem ser retomadas e ressignificadas conforme declarado pelo professor.

$\mathrm{Na}$ expectativa de levar a Química de forma mais prazerosa, divertida e significativa para o estudante, sugere-se aqui a inserção de HQs com conceitos químicos como estratégia didática, sendo aferida a $H Q$ como relevante no processo de ensino-aprendizagem na percepção desse docente. Salienta-se aqui que o Quadrinho, além das características elencadas, pode também, em suas vertentes ilustrativas, tornar-se um facilitador na compreensão do mundo submicroscópico, podendo proporcionar uma melhor compreensão, por exemplo, de analogias utilizadas na apropriação de modelos atômicos e reações químicas, por parte dos estudantes. Finaliza-se com a recomendação de que outras HQs sejam desenvolvidas e pesquisadas, envolvendo outros tópicos de química, para uma melhor compreensão do processo de ensino-aprendizagem de conteúdos científicos.

\section{REFERÊNCIAS}

AL-BALUSHI, Sulaiman M. The effect of different textual narrations on students' explanations at the submicroscopic level in chemistry. Eurasia Journal of Mathematics, Science \& Technology Education, v.9, n.1, p.3-10, 2013. 
ANDERSSON, Bjorn. Pupils' explanations of some aspects of chemical reactions. Science Education. v. 70, n. 5, p. 549-563, 1986.

ANSELMO, Zilda Augusta. Histórias em Quadrinhos. SN: São Paulo. 1975.

ARAÚJO, Denise Lino. O que é (e como faz) sequência didática?. Entrepalavras, v. 3, n. 1, p. 322-334, 2013.

BARDIN, Laurence. Análise de conteúdo. São Paulo: Edições 70, 2011, 229p.

BOYLE, Elizabeth.A, Engagement in digital entertainment games: A systematic review. Computers in Human Behavior, p. 771-780, 2012.

BRITO, Márcia de Sousa Terra; COSTA, Marcio da. Práticas e percepções docentes e suas relações com o prestígio e clima escolar das escolas públicas do município do Rio de Janeiro. Revista Brasileira de Educação, v. 15, n. 45, p. 500-510, 2010.

CARVALHO, Anna Maria Pessoa de. O ensino de ciências e a proposição de sequências de ensino investigativas. Ensino de ciências por investigação: condições para implementação em sala de aula. São Paulo: Cengage Learning, p. 1-20, 2013.

CASTILHO, Dalva; SILVEIRA, Katia; MACHADO, Andréa. Química como Investigação e Reflexão. Química Nova na Escola, n.9, 1999.

COSTA GONDIM, Maria Stela; MENDES, Mírian Rejane Magalhães. Concepções alternativas na formação inicial de professores de química: pressuposto para uma reflexão sobre o processo ensino/aprendizagem. 2012. Disponível em www.if.usp.br, acessado em 30 de dezembro de 2019.

CUNHA, Marcia Borin. Jogos no ensino de química: considerações teóricas para sua utilização em sala de aula. Química Nova na Escola, São Paulo,[s. L.], v. 34, n. 2, p. 92-98, 2012.

FERREIRA, Poliana; JUSTI, Rosária. Modelagem e o "Fazer Ciência". Química Nova na Escola, n.28, 2008.

GOUW, Ana Maria Santos; BIZZO, Nelio Marco Vincenzo. A percepção dos jovens brasileiros sobre suas aulas de Ciências. Educar em Revista, n. 60, p. 277-292, 2016.

KUNDLATSCH, Aline. Enquadrando as Histórias em Quadrinhos na formação inicial de professores de Química: possibilidades e limites. Dissertação de Mestrado. Universidade Estadual Paulista. 2019.

LOCATELLI, Solange; ARROIO, Agnaldo. Metacognition and chemical education: an experience in teaching geometrical isomerism. Natural Science Education, v.37, n.2, p.1826, 2013. 
MARTINS, Angela Maria; MACHADO, Cristiane; FURLANETTO, Ecleide Cunico. Mediação de conflitos em escolas: entre normas e percepções docentes. Cadernos de Pesquisa, v. 46, n. 161, p. 566-592, 2016.

MASETTO, Marcos. Didática: A aula como centro. São Paulo: FTD, 1996, p.42-47.

MOREIRA, Marco Antonio. Modelos científicos, modelos mentais, modelagem computacional e modelagem matemática: aspectos epistemológicos e implicações para o ensino. Revista Brasileira de Ensino de Ciência e Tecnologia, v.7, n.2, 2014.

MORTIMER, Eduardo Fleury; CHAGAS, Alexander Nilson; ALVARENGA, Vera Tamberi. Linguagem científica versus linguagem comum nas respostas escritas de vestibulandos. Investigações em ensino de ciências, v. 3, n. 1, p. 7-19, 2016.

MOYA, Antonio. A História das Histórias em Quadrinhos. L\&M. 1980.

PIAGET, Jean. A Equilibração das Estruturas Cognitivas: problema central do desenvolvimento. Rio de Janeiro: Zahar. 1976.

PIERINI, Max F. et al. Aprendizagem baseada em casos investigativos e a formação de professores: o potencial de uma aula prática de volumetria para promover o ensino interdisciplinar. Química Nova na Escola. 2015.

SANTOS, Wildson Luiz Pereira dos; SCHNETZLER, Roseli Pacheco. Educação em química: compromisso com a cidadania. 2003.

SASSERON, Lúcia Helena; CARVALHO, Anna Maria Pessoa. Almejando a alfabetização científica no ensino fundamental: a proposição e a procura de indicadores do processo. Investigações em ensino de ciências, v. 13, n. 3, p. 333-352, 2016.

SCHNETZLER, Roseli Pacheco. A pesquisa em ensino de química no Brasil: conquistas e perspectivas. Química nova, v. 25, n. supl 1, p. 14-24, 2002.

SILVA, Dirceu. Estudo das Trajetórias Cognitivas de Alunos no Ensino da Diferenciação dos Conceitos de Calor e Temperatura. São Paulo. FEUSP. Tese de Doutorado. 1995.

TESTONI, Leonardo André. Histórias em Quadrinhos e o Ensino de Física: unindo ciência arte e educação. Novas Edições Acadêmicas. 2015

TESTONI, Leonardo André; ABIB, Maria Lucia Vital dos Santos; AZEVEDO, Maria Nizete. Processos criativos didáticos no estágio de futuros professores de física. Ensino \& Pesquisa, 2017.

VASCONCELLOS, Túlio Flávio; RODRIGUES, Acássio Paiva; GOMES, Geovany Amorim. Concepções alternativas dos modelos de átomos dos alunos do ensino médio de uma escola pública em Sobral-CE. Atas do III Conedu. 2016. 


\section{DADOS DOS AUTORES}

\section{LEONARDo ANDré TeSTONI}

Doutor em Educação (ênfase em Ciências e Matemática) pela Universidade de São Paulo. Docente da Universidade Federal de São Paulo (UNIFESP). Coordenador do Programa de Pós-graduação em Ensino de Ciências e Matemática da Universidade Federal de São Paulo (PECMA - UNIFESP). leonardo.testoni@unifesp.br

\section{Solange Wagner Locatelli}

Doutora em Ensino de Ciências (Química) pela Universidade de São Paulo (USP). Docente da Universidade Federal do ABC.sol.locatelli@gmail.com

\section{Simone Alves de Assis Martorano}

Doutorado em Ensino de Ciências (Química) pela Universidade de São Paulo. Docente da Universidade Federal de São Paulo (UNIFESP). sialvesmartorano@gmail.com

\section{Marco Antonio dos SAntos}

Graduado em Química e Pedagogia. Mestre em Educação. Professor dos Colégio Parthenon Bom Clima e Neolatino.masantos@parthenonplus.com

Submetido em: 18-04-2020

Aceito em: 01-02-2021 